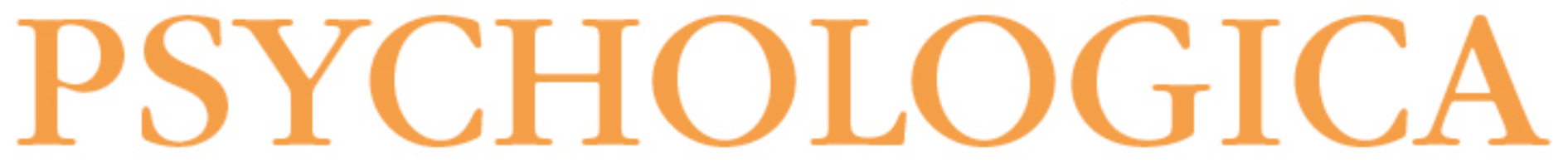

\title{
Transição para a idade adulta e adultez emergente: adaptação do Questionário de Marcadores da Adultez junto de jovens portugueses
}

Autor(es): $\quad$ Mendonça, Marina; Andrade, Cláudia; Fontaine, Anne Marie

Publicado por: Imprensa da Universidade de Coimbra

URL

persistente: URI:http://hdl.handle.net/10316.2/5471

DOI: DOI:http://dx.doi.org/10.14195/1647-8606_51_10

Accessed : $\quad$ 26-Apr-2023 01:38:41

A navegação consulta e descarregamento dos títulos inseridos nas Bibliotecas Digitais UC Digitalis, UC Pombalina e UC Impactum, pressupõem a aceitação plena e sem reservas dos Termos e Condições de Uso destas Bibliotecas Digitais, disponíveis em https://digitalis.uc.pt/pt-pt/termos.

Conforme exposto nos referidos Termos e Condições de Uso, o descarregamento de títulos de acesso restrito requer uma licença válida de autorização devendo o utilizador aceder ao(s) documento(s) a partir de um endereço de IP da instituição detentora da supramencionada licença.

Ao utilizador é apenas permitido o descarregamento para uso pessoal, pelo que o emprego do(s) título(s) descarregado(s) para outro fim, designadamente comercial, carece de autorização do respetivo autor ou editor da obra.

Na medida em que todas as obras da UC Digitalis se encontram protegidas pelo Código do Direito de Autor e Direitos Conexos e demais legislação aplicável, toda a cópia, parcial ou total, deste documento, nos casos em que é legalmente admitida, deverá conter ou fazer-se acompanhar por este aviso. 
NÚMERO 51

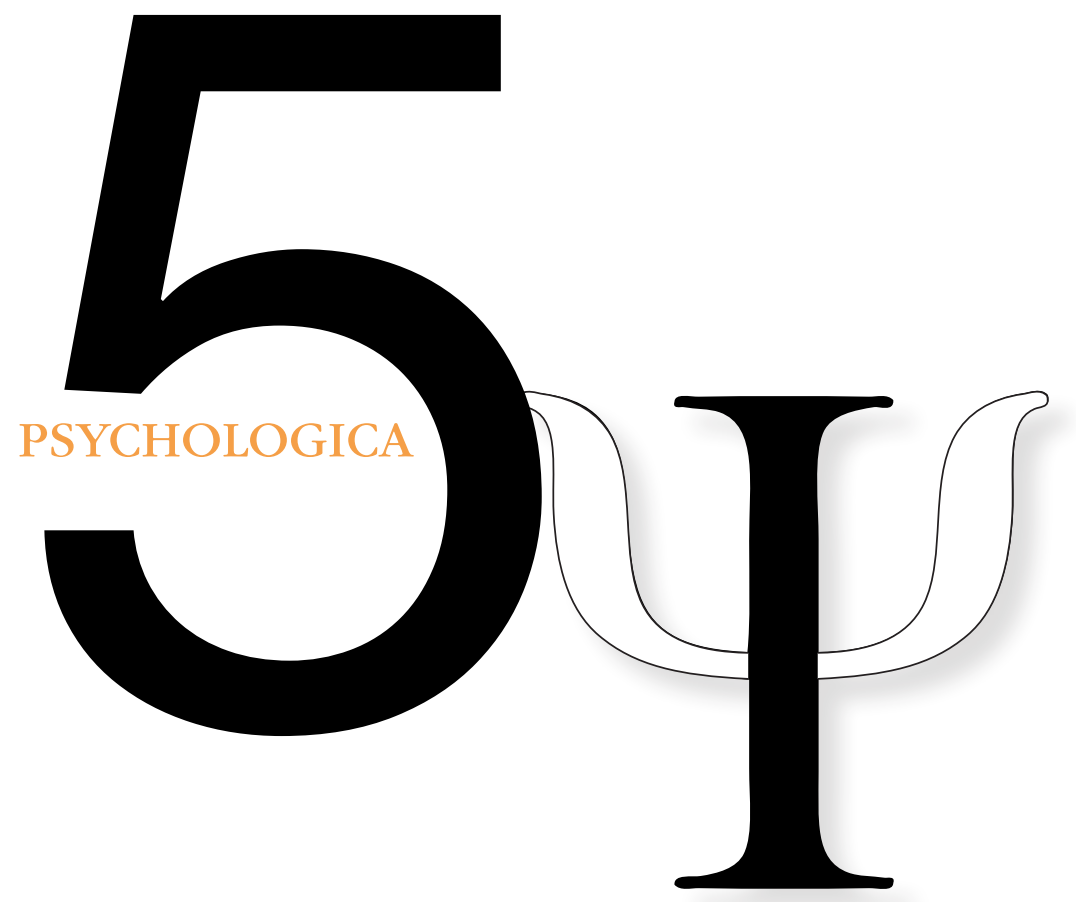

IMPRENSA DA UNIVERSIDADE DE COIMBRA

FACULDADE DE PSICOLOGIA E DE CIÊNCIAS DA EDUCAÇÃO DA UNIVERSIDADE DE COIMBRA 


\title{
Transição para a Idade Adulta e Adultez Emergente: Adaptação do Questionário de Marcadores da Adultez junto de Jovens Portugueses
}

\author{
Marina Mendonça', Cláudia Andrade² \& Anne Marie Fontaine³
}

O presente artigo tem como principal objectivo adaptar o instrumento Questionnaire of Markers of Adulthood-OMA (Arnett, 2001), junto de jovens portugueses. Inspirado no conceito de Adultez Emergente, um conjunto de marcadores psicológicos, biológicos, sociais e contextuais de transição para a idade adulta foram avaliados a partir de 37 itens, junto de uma amostra de 224 estudantes universitários. Análises factoriais exploratórias e confirmatórias evidenciaram uma estrutura com cinco factores. Os resultados deste estudo confirmam a importância dos marcadores psicológicos como elementos nucleares na definição da idade adulta. Adicionalmente, para os jovens que ainda não se percepcionam completamente adultos, a independência financeira surge como um elemento crucial na sua definição da idade adulta. Este estudo reforça a importância atribuída, por outros autores contemporâneos, a esta fase emergente da vida e oferece um instrumento capaz de avaliar, de forma fiável e válida, a importância relativa dos marcadores de transição na conceptualização da idade adulta em Portugal.

PALAVRAS-CHAVE: adultez emergente; marcadores de adultez; qualidades psicométricas.

\section{Introdução}

Nas sociedades contemporâneas, uma conjugação de factores sociais, políticos e económicos têm contribuído para a ocorrência de profundas alterações no processo de transição para a idade adulta. A existência de um mercado de trabalho cada vez mais complexo e competitivo tem conduzido a percursos escolares, também, mais longos e a inserções laborais mais tardias e instáveis. Consequentemente,

\footnotetext{
1 Estudante de doutoramento (Faculdade de Psicologia e de Ciências da Educação da Universidade do Porto, Rua Dr. Manuel Pereira da Silva, 4200-392 Porto, Telefone: 226079700, E-mail: mmendonca@fpce.up.pt) 2 Equiparada a Professora Adjunta, Escola Superior de Educação de Coimbra.

3 Professora Catedrática, Faculdade de Psicologia e de Ciências da Educação da Universidade do Porto.
} 
assiste-se a um prolongamento do período de dependência dos jovens em relação à família de origem. A emergência de novos valores na sociedade cria, também, condições para o aparecimento de projectos e estilos de vida alternativos que escapam à sequência normativa de passagem para a vida adulta. Deste modo, os acontecimentos sociais que, tradicionalmente, marcavam a entrada na idade adulta como a conclusão dos estudos, o ingresso no mundo do trabalho, a saída da casa dos pais, o casamento e a parentalidade assumem hoje contornos menos lineares, perdendo o seu valor legitimador do estatuto de adulto, especialmente junto de jovens com formação académica superior e de origem urbana. Assim, diversos autores destacam que as condições para se "ser adulto" parecem ter-se alterado, na medida em que as tarefas desenvolvimentais associadas a este período de vida se tornaram mais exigentes do ponto de vista psicológico e social (Arnett, 2004; Garrido \& Requera, 1996).

É nesta linha que se inscreve o presente estudo, que teve como objectivo adaptar um instrumento de avaliação dos marcadores de adultez desenvolvido por Arnett (2001), a jovens portugueses. Este instrumento permite avaliar o modo como a idade adulta é actualmente conceptualizada e verificar se a perspectiva dos jovens portugueses assume contornos semelhantes àqueles encontrados em estudos recentes noutros países.

Começaremos por evidenciar as principais características deste período, denominado por Arnett de Adultez Emergente, e verificar em que medida este período se encontra presentemente representado na sociedade portuguesa. Num segundo momento, apresentaremos as fases de adaptação do instrumento e debruçar-nos-emos sobre os marcadores de adultez e, ainda, sobre o modo como os jovens portugueses conceptualizam a idade adulta.

\section{Adultez Emergente}

Alterações nos padrões sociais e culturais de países industrializados levam a que as tarefas que, tradicionalmente, marcavam o início da idade adulta, como o casamento e a parentalidade, sejam adiadas. Tendo em conta estas mudanças, Jeffrey Arnett $(1998,2000,2001,2004)$ propôs a delimitação de uma nova fase no ciclo de vida dos indivíduos, a qual designou por adultez emergente. O autor define esta fase desenvolvimental como um período, mais ou menos extenso, entre o fim da adolescência e o início da idade adulta, situando-se, preferencialmente, entre os 18 e 29 anos, durante o qual os indivíduos já não são adolescentes, mas, ainda, não possuem as características normativas da idade adulta. O seu modelo de análise, desta etapa desenvolvimental, faz-se com recurso a três argumentos 
específicos - (1) de natureza demográfica, (2) identitária e (3) subjectiva (Arnett, 2001, 2004, 2006).

No que diz respeito ao primeiro argumento, o autor sublinha que a terceira década da vida apresenta de uma imensa variabilidade demográfica, o que não acontece antes dos 18 anos e que desaparece a partir dos 30 anos. Diferentes configurações de coabitação (e.g., residir com pais, amigos/colegas, namorado/a ou sozinho); uma grande mobilidade geográfica e a passagem por múltiplos empregos, são alguns aspectos que destacam o carácter instável, exploratório e transitório deste período de vida. Esta diversidade poderá ser reflexo da liberdade conferida aos adultos emergentes, resultado, por um lado, de um menor controlo parental e, por outro lado, de uma menor pressão social para aderirem a modelos normativos de entrada na idade adulta (Arnett, 2004). Relativamente a este último aspecto, Côté $(2000,2006)$ alega que as sociedades actuais são caracterizadas pela anomia (ausência de normas sociais consensuais), carecendo de suportes institucionais e de modelos suficientemente salientes para ajudar a estruturar a transição para a idade adulta. Deste modo, dado o vasto leque de possibilidades com o qual os indivíduos se confrontam e o menor apoio externo para orientar as suas opções, os jovens ficam, para o melhor e para o pior, mais dependentes dos seus próprios recursos pessoais para construírem esses percursos de transição.

Este sentimento de liberdade de escolha é, no entanto, desafiado pela outra "face da moeda", ou seja, pela instabilidade, incerteza e dificuldade em criar ou aceder às oportunidades. A adultez emergente é, deste modo, também, um tempo para lidar com paradoxos, sendo, simultaneamente, um tempo de novas liberdades e de novos receios e novas frustrações (Arnett, 2004).

O segundo aspecto destacado por Arnett, refere-se às explorações identitárias presentes nesta fase do desenvolvimento. Adoptando a perspectiva de Erikson (1968), sobre o desenvolvimento da identidade, Arnett (2000) prevê que o processo de exploração identitária iniciado na adolescência irá intensificar-se na adultez emergente, dado que os jovens usufruem de um maior grau liberdade e autonomia. Essas explorações assumiriam também um carácter mais sério e menos transitório do que na adolescência. Erikson (1968) já havia reconhecido que factores sociais poderiam, excepcionalmente, prolongar a moratória psicossocial para além da adolescência. No entanto, cerca de cinquenta anos mais tarde, tal situação parece ter-se tornado normativa para certos grupos de jovens (Arnett, 2000; Côté, 2006). Dado que há um adiamento das responsabilidades inerentes aos papéis de adulto acompanhado pelo apoio financeiro dos pais durante este "período de espera" e a ausência de "pressão" externa, possibilita aos jovens uma exploração mais livre de diversas áreas de actividades profissionais até encontrarem a sua vocação. De facto, é possível assistir-se a diversos ensaios que se 
traduzem em alterações ou interrupções temporárias dos estudos, mudanças de área profissional, ou mesmo reingressos no sistema de ensino após um período de inserção profissional. No que diz respeito às relações amorosas, a presença de diferentes relacionamentos durante este período irá permitir aos adultos emergentes responderem à seguinte questão identitária: "Quem sou eu? Que tipo de pessoa poderá constituir um/a bom/a companheiro/a para a vida?" (Arnett, 2000, p.473). Assim, é possivel assistir-se a compromissos mais ou menos duradouros, com ou sem períodos de coabitação, que poderão, eventualmente, traduzir-se numa posterior união duradoura.

O último argumento apresentado por Arnett, a favor da conceptualização da adultez emergente como um período desenvolvimental distinto, envolve a percepção subjectiva do estatuto de adulto. Numa série de estudos realizados junto de estudantes universitários nos Estados Unidos, Arnett $(1998,2000)$ verificou que a maior parte deles manifestavam um sentimento ambivalente relativamente à percepção de si como adulto, isto é, sentiam-se parcialmente adolescentes e parcialmente adultos. Esta ambivalência começava a dissipar-se, no entanto, a partir do final da terceira década da vida, isto é, à medida que os jovens se aproximavam dos 30 anos.

Em síntese, Arnett baseia a teoria da adultez emergente sobre perspectivas clássicas do desenvolvimento psicológico, nomeadamente do desenvolvimento identitário de Erikson, sem esquecer a importância de aspectos sociológicos que condicionam a entrada para a idade adulta. A adultez emergente é o resultado de forças culturais presentes em sociedades industrializadas e pós-industrializadas (Arnett, 1997, 2000, 2001), onde os princípios vigentes do individualismo tornaram as práticas de socialização mais flexíveis e diversificadas, e a complexificação social proporcionou o adiamento de tarefas normativas de entrada na idade adulta. Verifica-se, assim, que o modelo tradicional de transição para a idade adulta com metas e objectivos definidos sequencialmente no tempo (e.g., arranjar um emprego, casar, ter filhos) dá lugar a percursos cada vez mais complexos, irregulares e imprevisiveis. Para além disso, na adultez emergente, enquanto espaço de moratória psicossocial, surgem experiências e tarefas tradicionalmente vistas como aspectos de iniciação na vida, mas que no entanto perdem o seu carácter firme e duradouro a favor de uma "nova ética de vida" orientada para desafios, flexibilidade e descoberta de diferentes possibilidades de ser adulto (Sousa, 2005).

\section{Adultez emergente e o contexto sócio-cultural português}

Dado que a adultez emergente é um período que resulta de uma série de contingências presentes nas sociedades actuais, é pertinente analisar de que modo este periodo tem expressão junto de jovens portugueses. Como foi anteriormente 
referido, a adultez emergente é visível através da multiplicidade de percursos de transição e do adiamento dos papéis tradicionais de adulto em geral, ou seja, manifesta-se sob condições que abrem a possibilidade dos jovens usufruírem de um período de exploração independente. A sociedade portuguesa parece manifestar características que denunciam a presença desta fase desenvolvimental. Durante as últimas décadas, tem-se assistido ao prolongamento das trajectórias escolares e ao correspondente adiamento dos processos de transição para o mercado de trabalho, assim como a um aumento progressivo nas idades do casamento e do nascimento do primeiro filho, principalmente em jovens com formação universitária.

Os dados indicam que apesar de Portugal continuar a ser um dos países da União Europeia com taxas de escolarização mais baixas, o número de jovens que entraram no ensino superior duplicou de 1991 para 2001 (INE, 2004). De acordo com Guerreiro e Abrantes (2005), a massificação do ensino superior alterou significativamente os trajectos e projectos dos jovens portugueses, constituindo um contexto que proporcionou o adiamento da transição para a vida adulta, amplificou as expectativas em relação ao futuro e causou uma maior diversificação do perfil social dos jovens.

Contudo, uma maior escolarização não tem correspondido, necessariamente, a uma transição mais fácil para o mercado de trabalho. De facto, a elevação dos níveis de qualificação nem sempre é condição suficiente para o acesso ao emprego ou à estabilidade profissional. As taxas de desemprego em Portugal têm aumentado nos últimos anos, sendo que um terço dos desempregados tem menos de 30 anos (INE, 2004). Para além disso, uma proporção significativa dos jovens licenciados trabalha em empregos temporários, precários, com baixos salários e fora da sua área de especialização. Na verdade, entre 1991 e 2005, a taxa de desemprego entre jovens bacharéis e licenciados quadruplicou (Vieira, 2006). Deixa, assim, de ser possivel entender o tempo que medeia o fim da escolaridade e o exercício de uma profissão como um tempo curto e linear. Os percursos lineares (do ensino para o mercado de trabalho) tendem a ser substituidos por "percursos yo-yo", em que se observa alternância entre períodos de trabalho, desemprego e formação (Alves, 1998; Pais, 2001). Estas mudanças têm dificultado e alterado a transição para a idade adulta em Portugal. $\mathrm{O}$ acesso ao estatuto de adulto passa agora por um período de indeterminação e implica muitas vezes o recurso ao apoio parental em termos financeiros e residenciais (Andrade, 2006; Guerreiro \& Abrantes, 2004).

De facto, um dos aspectos que caracteriza a transição para a idade adulta é a independência económica relativamente à família de origem. Se bem que este aspecto seja eminentemente cultural, alguns indicadores, para o nosso país, assinalam que a independência económica é considerada bastante importante pelos jovens, embora dificilmente alcançável (Vasconcelos, 1998). Intimamente associada a estes factores de natureza económica, a coabitação entre gerações 
tem se tornado uma realidade mais comum em Portugal, como noutros países do Sul da Europa. Alguns dados sociológicos referem que o prolongamento da educação não levou os jovens a sair de casa para frequentar o ensino superior, pelo contrário, a proliferação das instituições de ensino superior permitiu a permanência dos jovens em casa dos pais enquanto realizam a sua formação. Assim, os pais, apesar de estarem dispostos a garantir uma ampla autonomia aos filhos, continuam a ser o principal recurso económico durante a transição para a idade adulta (Andrade, 2006; Cavalli, 1997; Rossi, 1997).

As transformações estruturais nos sistemas de ensino e no mundo do trabalho têm, também, influenciado as condições da vida familiar e matrimonial dos jovens casais. Os dados demográficos indicam que os jovens portugueses estão hoje mais relutantes em casar e ter filhos cedo. Desde os anos 90 que se tem assistido a um aumento gradual das idades de casamento e nascimento do primeiro filho ${ }^{4}$. Factores económicos e culturais parecem cruzar-se na justificação deste fenómeno. $\mathrm{O}$ adiamento ou a recusa de projectos familiares pode encontrar-se associado a uma nova atitude dos jovens perante a entrada na idade adulta. Segundo Guerreiro e Abrantes (2007), os jovens valorizam este tempo de experimentação, isento de grandes preocupações e encargos, antes de decidir assumir projectos familiares que requerem um maior nivel de responsabilidade. Adicionalmente, o controlo da natalidade e a mudança de atitudes face à sexualidade permite viver as relações de forma mais descomprometida. Deste modo, os jovens podem fazer as suas escolhas de forma mais autónoma, pelo menos em termos afectivos, adaptando-se a novos padrões de conjugalidade e de realização pessoal que, até há algumas décadas, não eram tão frequentes (Cavalli, 1997; Vasconcelos, 1998).

Os estudos efectuados, junto de jovens portugueses, em fase de transição para a idade adulta, concluem que os jovens têm uma visão da vida a dois tempos: um primeiro período isento de grandes responsabilidades e dedicado à experimentação e aventura, seguido de um momento de responsabilidade e estabilidade, onde os projectos familiares começam a ser implementados (Andrade, 2006; Guerreiro e Abrantes, 2004). Deste modo, a transição para a idade adulta é vista como um período relativamente longo, após a adolescência, em que a vida é vivida de forma descontraída e descomprometida e onde é suposto os jovens "gozarem a vida" e aproveitar ao máximo as oportunidades que surgem. Os jovens portugueses pretendem durante a terceira década da vida aderir a este modelo de vida

\footnotetext{
4 Segundo as estatísticas demográficas do Instituto Nacional de Estatísticas (Barrisco, 2006), a idade média de casamento não se alterou significativamente entre 1960 e 1990, contudo, a partir de 1990 verificou-se um progressivo aumento em ambos os sexos. Os dados relativos à média de idade do primeiro casamento são mais recentemente de 28.6 para os homens e de 26.9 para as mulheres. Em 1990 os jovens do sexo masculino casavam-se em média aos 26.2 e as jovens aos 24.2. Observa-se assim a um aumento de cerca de dois anos na média da idade de casamento em apenas 14 anos.
} 
hedonista, para a partir dos 30 anos, "assentar e assumir compromissos", isto é, integrar padrões de vida mais convencionais (Andrade, 2006; Guerreiro e Abrantes, 2004). É possível, deste modo, encontrar nesta visão da juventude portuguesa a manifestação deste período de adultez emergente, conceptualizada por Arnett a partir da sociedade norte americana.

\section{Marcadores de entrada na idade adulta}

Em que momento da vida um indivíduo se torna adulto? A investigação sobre a transição para a idade adulta tem incidido, fundamentalmente, na análise de transições consideradas normativas (e.g., ter um emprego, casar, ter filhos), que marcam a entrada na idade adulta.

Arnett $(1998,2000)$ verificou, a partir de uma série de indicadores identificados como etapas simbólicas da entrada na idade adulta (e.g., marcadores biológicos, legais, sociais, psicológicos, associados a competências familiares e cumprimento de normas sociais), que a adultez é sobretudo dependente de características pessoais que apontam para a capacidade do individuo ser auto-suficiente do ponto de vista psicológico e instrumental (e.g., ser responsável, ser capaz de tomar decisões autonomamente e ser economicamente independente).

Estudos na área da sociologia sugerem, no entanto, que os marcadores sociais continuam a ter um papel preponderante na percepção dos indivíduos como adultos e no modo como os jovens representam a adultez. Shanahan, Porfeli e Mortimer (2005) analisaram a importância de factores sociais e individuais na auto-percepção do estatuto de adulto e constataram que variáveis internas de maturidade só se tornavam salientes na ausência de transições normativas. Westberg (2004), por sua vez, verificou que, a experimentação de papéis de adulto (sobretudo a parentalidade) é determinante para os jovens se percepcionarem como adultos, embora a importância atribuída a estes papéis não é valorizada pelos jovens na antecipação do que significa ser adulto.

Adicionalmente, a valorização destes marcadores diverge segundo as culturas (Arnett, 1998). Os resultados encontrados por Arnett poderão ser interpretados como reflectindo valores individualistas característicos da cultura norte americana. Schlegal e Berry (1991) sugerem que em sociedades mais tradicionais e colectivistas os indivíduos privilegiam aspectos associados à aquisição dos tradicionais papéis sociais de adulto. Portugal faz parte de uma tradição cultural latina e católica caracterizada pela partilha de valores colectivistas, nomeadamente familiares (Matias \& Fontaine, 2005; Fontaine, Andrade, Matias, Gato \& Mendonça, 2006). Deste modo, poderia esperar-se uma maior valorização de marcadores que 
salientassem papéis e transições familiares na conceptualização do estatuto de adulto. Contudo, estudos recentes em sociedades com características colectivistas, nomeadamente Argentina e Israel, têm revelado resultados pouco conclusivos (Facio \& Micocci, 2003; Mayseless \& Scharf, 2003).

154 Parece, assim, que alterações no processo de transição para a idade adulta, decorrentes de mudanças sociais mais globais em confronto com os valores culturais dominantes, são responsáveis por novos modos de pensar e definir a transição para a idade adulta.

\section{Objectivos do estudo}

Portugal parece reunir um conjunto de características que favorecem a manifestação de um período de adultez emergente. Tendo em conta percursos de transição marcados pela instabilidade e pela dificuldade em aceder a experiências que, tradicionalmente, marcavam a entrada na idade adulta, assim como a emergência de novos valores relativamente a esta fase da vida, um dos principais objectivos deste estudo é o de adaptar um instrumento que permite avaliar o modo como os jovens portugueses conceptualizam a idade adulta.

Deste modo, o instrumento - Questionário de Marcadores de Adultez (Arnett, 2001) irá ser avaliado junto de estudantes universitários, uma vez que é o grupo que parece reunir mais condições para a vivência desta etapa desenvolvimentals. Inúmeras investigações têm sido realizadas com o Questionário de Marcadores de Adultez (OMA), fundamentalmente junto da população americana. Dada a inexistência de estudos na população portuguesa sobre esta temática, optou-se por se proceder à validação e avaliação das qualidades psicométricas deste instrumento. A sua administração irá permitir averiguar quais os acontecimentos que marcam a entrada na idade adulta e quais as características que os jovens reconhecem como mais relevantes na sua definição. Já que a actual conjuntura influencia a percepção que os jovens têm de si próprios como adultos, a avaliação da auto-percepção do estatuto de adulto permite apreciar em que medida os estudantes do ensino superior se sentem adultos e se esta auto-percepção varia em função da independência residencial, isto é, do facto de viverem ou não com os pais. Finalmente, pretende-se, ainda, verificar se o facto dos jovens se sentirem ou não adultos influencia o modo como conceptualizam a idade adulta.

\footnotetext{
5 A adultez emergente encontra-se fortemente associada ao contexto universitário e a níveis sócioeducacionais mais favorecidos onde os jovens têm acesso a recursos e apoios por parte da família (Arnett, 2006, Côté, 2006; Tanner, 2006).
} 


\section{Método}

Este estudo encontra-se organizado em duas partes. Na primeira parte vai ser apresentado o processo de adaptação e validação do Questionário de Marcadores de Adultez (QMA), através de análises factoriais exploratórias, análises factoriais confirmatórias e a avaliação da fiabilidade das escalas. Na segunda parte, será apresentado um estudo diferencial sobre a auto-percepção do estatuto de adulto dos estudantes e a sua variação em função da independência residencial, seguido da avaliação dos marcadores considerados mais relevantes na definição da idade adulta e a sua variação em função da auto-percepção do estatuto de adulto.

\subsection{Amostra}

Os dados deste estudo foram recolhidos junto de uma amostra de 224 estudantes universitários (77 rapazes e 147 raparigas), de ambos os sexos e pertencentes a diversas áreas do Ensino Superior (Ciências Sociais e Humanas, Economia, Engenharia e Ciências Naturais) de Universidades Públicas e Privadas do Norte e Centro de Portugal. As idades variam entre um mínimo de 18 anos e um máximo de 30 , sendo a média de idades de 22 anos. $67.41 \%$ dos sujeitos afirmou pertencer a um nível socioeconómico médio, $13.84 \%$ a um nível socioeconómico alto e $17.41 \%$ a um nível socioeconómico baixo. Relativamente à situação familiar, $96 \%$ dos estudantes, da amostra,são solteiros e sem filhos. No que se refere à situação residencial, observa-se que cerca de metade da amostra vive com os pais (46\%). Os restantes sujeitos afirmaram viver com colegas/amigos ( $28 \%)$, sozinhos ( $12 \%)$, com outros familiares (6\%), com namorado/a (5\%) ou cônjuge (3\%).

\subsection{Instrumentos}

Foi solicitado aos sujeitos o preenchimento de um questionário de 39 itens Questionário de Marcadores de Adultez (QMA) indicando o grau de concordância com os critérios de adultez que lhes eram apresentados (em que medida pensa que cada uma destas actividades elou acontecimentos é fundamental para que a pessoa seja considerada adulta?). Este questionário constitui uma adaptação do Questionnaire of Markers of Adulthood, desenvolvido por Arnett (2001), a partir de estudos piloto e de pesquisas na área da sociologia, antropologia e psicologia (Arnett, 1994, 1997, 1998), abrangendo, assim, um leque diversificado de possíveis critérios associados à transição para a idade adulta. Na sua versão original, o questionário encontra-se organizado nas seguintes subescalas: individualismo, competências familiares, adesão às normas, transições biológicas, transições legais/cronológicas e transições sociais. A estrutura original deste instrumento 
foi exclusivamente elaborada a partir de critérios teóricos e conceptuais. A consistência interna obtida para as subescalas organizadas deste modo foi considerada pelo autor como satisfatória 6 .

Neste instrumento encontra-se, ainda, uma questão fechada relativa à auto-percepção do estatuto de adulto (achas que já atingiste a idade adulta?) sendoIhes facultada 3 opções de resposta (sim, não, e sim e não).

Foi ainda solicitado o preenchimento de um breve questionário sócio-demográfico com o objectivo de caracterizar a amostra, nomeadamente em termos residenciais.

\subsection{Procedimento}

A versão portuguesa do instrumento foi obtida da tradução do original a partir de um processo que combina vários métodos: tradução directa, retroversão e comparação das duas versões. Optou-se, também, por substituir a opção de resposta "sim" e "não", utilizada no estudo original, por uma escala de tipo likert que variava de 1 a 4 (discordo totalmente, discordo, concordo, concordo totalmente) permitindo recolher respostas mais diferenciadas e efectuar análises de dados mais diversificadas.

Da escala original foi retirado um item pertencente à subescala transições cronológicas/legais (Ter 21 anos), por não se adequar à realidade portuguesa. Decidiu-se introduzir no instrumento o item viver com o/a namorado/a por corresponder a um aspecto relevante na realidade dos jovens portugueses.

Dado que o estudo foi efectuado junto de uma amostra de conveniência, os dados foram recolhidos, quer a partir de administrações colectivas a turmas do ensino superior, quer a partir de solicitações individualizadas em contextos de estudo e trabalho, como bibliotecas. O preenchimento do instrumento foi precedido de uma breve exposição do objectivo do estudo e do modo de resposta pretendido, sendo, ainda, assegurada a confidencialidade e anonimato das respostas. Em média, o preenchimento do questionário demorou cerca de 15 minutos.

\subsection{Resultados}

\subsection{1: Estudo das qualidades psicométricas do instrumento QMA}

A avaliação das qualidades psicométricas do instrumento foi efectuada a partir da análise do poder discriminativo dos itens, da estrutura factorial exploratória e

\footnotetext{
6 A fiabilidade deste instrumento foi avaliada por Arnett (2001), junto de uma amostra de 519 sujeitos, entre os 13 e 55 anos, revelando os seguintes valores de consistência interna ( $\alpha$ Cronbach): individualismo (.57); competências familiares (.88), adesão a normas (.84), transições biológicas (.76), transições cronológicas/legais (.55) e transições sociais (.60).
} 
confirmatória e da apreciação da respectiva consistência interna das dimensões evidenciadas a partir das análises anteriores.

\subsubsection{Poder discriminativo dos itens}

O poder discriminativo dos itens foi avaliado a partir da distribuição da percentagem das respostas dos sujeitos, pelas várias alternativas propostas. Considerou-se como critério de eliminação do item, sempre uma das respostas recolhia mais de $70 \%$ de adesão. Nenhum item apresentou uma concentração de respostas superior a este valor, não tendo sido por isso eliminado nenhum item.

\subsubsection{Análises factoriais exploratórias}

No sentido de avaliar o modo como este instrumento se organizava na população estudada, procedeu-se, num primeiro momento, a uma análise factorial exploratória, análise em componentes principais7 seguida de rotação varimax. Foi encontrada uma estrutura factorial de 11 factores, explicando $71.65 \%$ da variância. Tendo em conta que os últimos factores eram de difícil interpretação e a curva do scree plot sugeria uma estrutura factorial de 5 ou 6 factores, procedeu-se a novas análises factoriais. Optou-se por uma estrutura de 5 factores tendo em consideração a percentagem da variância explicada, o quadro teórico de base e a consistência interna das subescalas.

Deste modo, os cinco factores extraídos explicam no seu conjunto $50.89 \%$ da variância das respostas, sendo $13.81 \%$ explicada pelo primeiro factor; $11.75 \%$ explicada pelo segundo; $11.27 \%$ pelo terceiro; $8.58 \%$ pelo quarto e $5.46 \%$ pelo quinto factor (ver quadro 1).

Quadro 1. Análise factorial exploratória (rotação varimax) do Questionário de Marcadores de Adultez (OMA)

\begin{tabular}{c|ccccc}
\hline Itens & Factor 1 & Factor 2 & Factor 3 & Factor 4 & Factor 5 \\
\hline 23 &, 804 & & & \\
35 &, 775 & & & \\
36 &, 766 & & & \\
22 &, 761 & & & \\
32 &, 730 & & & \\
31 &, 719 & & & \\
12 &, 659 & & & \\
17 &, 643 & & & \\
6 & &, 792 & & \\
4 & &, 764 & & \\
13 & &, 692 & & \\
\end{tabular}

7 Critério de Kaiser: valor próprio superior a 1. 


\begin{tabular}{|c|c|c|c|c|c|}
\hline Itens & Factor 1 & Factor 2 & Factor 3 & Factor 4 & Factor 5 \\
\hline 9 & & ,645 & & & \\
\hline 8 & &, 584 & & & \\
\hline 39 & & ,552 & & & \\
\hline 3 & & ,539 & & & \\
\hline 18 & & , 423 & & & \\
\hline 38 & & ,396 & & & \\
\hline 37 & & & 813 & & \\
\hline 30 & & & ,808 & & \\
\hline 28 & & & ,700 & & \\
\hline 24 & & & ,663 & & \\
\hline 34 & & & ,659 & & \\
\hline 7 & & & ,639 & & \\
\hline 16 & & &, 575 & & \\
\hline 15 & & & 448 & & \\
\hline 20 & & & .379 & & \\
\hline 2 & & & & ,733 & \\
\hline 11 & & & & 687 & \\
\hline 19 & & & & 670 & \\
\hline 1 & & & &, 596 & \\
\hline 26 & & & &, 542 & \\
\hline 14 & & & & ,499 & \\
\hline 21 & & & &, 363 & \\
\hline 33 & & & & &, 550 \\
\hline 10 & & & & &, 525 \\
\hline 25 & & & & &, 510 \\
\hline 27 & & & & & ,416 \\
\hline 29 & & & & & ,350 \\
\hline $\begin{array}{l}\text { \% Variância } \\
\text { explicada }\end{array}$ & 13.81 & 11.75 & 11.27 & 8.58 & 5.47 \\
\hline
\end{tabular}

Embora todos os itens apresentassem valores de saturação superiores a .30, constatou-se que 4 itens apresentavam saturações próximas em mais do que um factor. Trata-se dos itens: estar comprometido numa relação amorosa prolongada (saturações no factor 1 e 4); ter apenas um parceiro sexual (saturações no factor 2 e 3); ser responsável pelos seus actos saturações no factor 2 e 3); não ter laços emocionais profundos com os pais (saturações no factor 2 e 5). Visto serem itens teoricamente relevantes, decidiu-se mantê-los no instrumento, desde que não prejudicassem a consistência interna das escalas e fossem teoricamente coerentes com o factor. Deste modo, foram realizadas análises de consistência das escalas e verificou-se que os valores de alfa de Cronbach aumentavam quando se incluía o item: estar comprometido numa relação amorosa prolongada no factor 4; ter apenas um parceiro sexual no factor 3; e ser responsável pelos seus actos no factor 3. O item não ter laços emocionais profundos com os pais foi eliminado. 
Comparando a estrutura factorial proposta por Arnett (2001) com a actual, verifica-se que o único factor que corresponde exactamente à dimensão original foi o factor 1, correspondendo à escala competências familiares. Os itens da escala identificada como "individualismo" por Arnett (2001) dividiram-se e saturaram dois factores, em que um se refere à capacidade do indivíduo para ser independente do ponto de vista económico e o outro do ponto de vista emocional, dando origem a duas subescalas que denominámos de independência financeira (factor 4) e maturidade emocional (factor 5), respectivamente. Verificou-se, ainda, uma fusão das escalas originais "transições biológicas", "transições legais/cronológicas" e "transições sociais", cujos itens saturam num único factor (factor 2), que designámos por transições normativas. Finalmente, o factor 3 é composto por todos os itens que na estrutura original compunham a subescala "adesão às normas" e à qual se junta, nesta nova estrutura, o item ser responsável pelos seus actos. Esta subescala diz respeito a itens de cumprimento de regras sociais e evitamento de comportamentos de risco, pelo que se decidiu manter o nome da escala adesão às normas.

O estudo da consistência interna de cada factor, a partir desta estrutura factorial, revelou-se satisfatório ${ }^{8}$ embora com valores ligeiramente mais baixos para a subescala maturidade emocional.

\subsubsection{Análise Factorial Confirmatória}

Com o objectivo de confirmar a estrutura anterior e efectuar uma selecção criteriosa dos itens, os dados foram, também, submetidos a análises factoriais confirmatórias com recurso ao programa estatístico AMOS 16 (Analysis of Moment Structure). Para tal procedeu-se ao desenho e avaliação do modelo obtido a partir da análise factorial exploratória efectuando-se análises factoriais confirmatórias para cada um dos factores separadamente. Através deste processo pretendeu-se, também, avaliar a permanência dos itens no instrumento que saturavam em mais do que um factor na análise anterior.

A qualidade de ajustamento global do modelo foi avaliada através de vários parâmetros: índice de bondade do ajustamento (GFI), o índice de bondade do ajustamento ajustado (AGFI), o índice de ajustamento comparativo (CFI), a raiz quadrada média do erro de aproximação e qui-quadrado9. Ao longo deste processo, decidiu-se, apenas, eliminar o item "estar comprometido numa relação amoroso

8 Valores de consistência interna ( $\alpha$ de Cronbach): competências familiares (.91); transições normativas (.82), adesão às normas (.85), independência financeira (.76) e maturidade emocional (.64).

9 De uma forma geral, um GFI e um AGFI de .90 ou superiores (valores acima de .95 são indicativos de uma ajustamento muito bom), um CFI de .95 ou superior, e um RMSEA de .80, ou inferior, indicam um ajustamento do modelo. O qui-quadro não deverá ser significativo, no entanto, esta estatística é sensível à dimensão da amostra. Deste modo, para o ajustamento dos modelos ser considerado adequado, 
prolongada" por comprometer estatisticamente factor 4. De uma forma geral, os índices de ajustamento para as escalas finais são satisfatórios (Quadro 2), com excepção das subescalas competências familiares e transições normativas, que apresentam alguns parâmetros de ajustamento ligeiramente aquém dos valores recomendados por alguns autores (Arbuckle, 1997; Tabachnik \& Fidell, 2001). Os valores de consistência interna obtidos não sofreram alterações nos seus valores. Deste modo, após as análises factoriais confirmatórias, a versão final do instrumento é composta por 37 itens que permitem avaliar de modo fiel e válida a conceptualização da idade adulta.

Quadro 2. Índices de bondade de ajustamento das escalas

\begin{tabular}{llllllll}
\hline \multicolumn{1}{c}{ Escalas } & $\mathrm{X}^{2}$ & $\mathrm{gl}$ & $\mathrm{X}^{2} / \mathrm{gl}$ & $\mathrm{GFI}$ & $\mathrm{AGFI}$ & $\mathrm{CFI}$ & $\mathrm{RMSEA}$ \\
\hline Competências Familiares & 37.58 & 12 & 3.13 & .95 & .88 & .98 & .09 \\
\hline Transições normativas & 78.23 & 30 & 2.61 & .93 & .88 & .94 & .08 \\
\hline Adesão às Normas & 38.95 & 23 & 1.69 & .96 & .92 & .98 & .06 \\
\hline Independência Financeira & 6.45 & 8 & .81 & .99 & .98 & 1.00 & .00 \\
\hline Maturidade Emocional & 1.58 & 5 & .32 & .99 & .99 & 1.00 & .00 \\
\hline
\end{tabular}

\subsection{2: Estudo diferencial de percepções e concepções de adultez}

\subsubsection{Auto-percepção do estatuto de adulto}

A fim de averiguar em que medida a sensação de "estar no meio", isto é, nem adolescente, nem adulto, observada em amostras norte americanas, era também observada em jovens portugueses, foi colocada uma questão acerca da auto-percepção do estatuto de adulto - Considera que já atingiu a idade adulta? Os resultados indicam que $48 \%$ dos estudantes da amostra responde "sim e não", 38\% responde "sim" e $12 \%$ responde "não". A maior parte dos estudantes não se considera totalmente adulta e a maioria parece colocar-se numa posição intermédia, considerando que, em certos aspectos, já atingiram a idade adulta, mas noutros não. Este resultado é coincidente com estudos anteriores (Arnett, 1994, 1997, 1998) que revelam a presença de um sentimento de ambivalência em relação à sua percepção de si como adulto, característico da adultez emergente.

Constata-se, ainda, a influência da emancipação da residência parental na auto-percepção do estatuto de adulto. Os jovens que não se encontram a residir com os pais percepcionam-se mais como adultos, do que os jovens que ainda não efectuaram esta transição $\left[\chi^{2}(2,222)=7.74 ; p<.02\right]$, situando-se numa posição de maior ambivalência quanto à sua definição do estatuto de adulto - "sim e não".

o quociente entre o valor de qui-quadrado e o número de graus de liberdade não deve ser superior a 3 (Arbuckle, 1997; Tabachnik \& Fidell, 2001). 


\subsubsection{Marcadores de adultez}

Num primeiro momento, tentou-se avaliar os marcadores que os jovens mais valorizavam na sua conceptualizavam da idade adulta, efectuando para tal uma análise das percentagens de concordância (soma das percentagens de respostas assinaladas com concordo e concordo totalmente) face aos marcadores apresentados no questionário (Quadro 3).

Quadro 3. Marcadores de Transição para a Idade Adulta percepcionados como Importantes ou Muito Importantes

\begin{tabular}{|c|c|c|}
\hline Escalas & Itens & $\begin{array}{c}\% \\
\text { Concordância }\end{array}$ \\
\hline & $\begin{array}{l}\text { 35. Quando um homem se torna capaz de gerir e cuidar de uma } \\
\text { casa. }\end{array}$ & 68 \\
\hline & $\begin{array}{l}\text { 36. Quando uma mulher se torna capaz de gerir e cuidar de uma } \\
\text { casa. }\end{array}$ & 67 \\
\hline \multirow{6}{*}{ 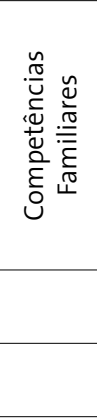 } & $\begin{array}{l}\text { 23. Quando um homem se torna capaz de cuidar de cuidar de } \\
\text { uma criança. }\end{array}$ & 61 \\
\hline & $\begin{array}{l}\text { 31. Quando um homem se torna financeiramente capaz de sus- } \\
\text { tentar uma família. }\end{array}$ & 57 \\
\hline & 22. Quando uma mulher se torna capaz de cuidar de uma criança. & 57 \\
\hline & $\begin{array}{l}\text { 32. Quando uma mulher se torna financeiramente capaz de sus- } \\
\text { tentar uma familia. }\end{array}$ & 55 \\
\hline & $\begin{array}{l}\text { 12. Ouando um homem se torna capaz de zelar pela segurança } \\
\text { física de uma família. }\end{array}$ & 51 \\
\hline & $\begin{array}{l}\text { 17. Quando um mulher se torna capaz de zelar pela segurança } \\
\text { física de uma família. }\end{array}$ & 45 \\
\hline \multirow{9}{*}{ 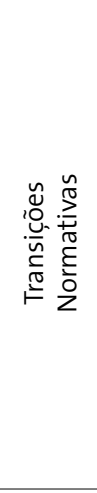 } & 39. Atingir o limite de crescimento físico. & 18 \\
\hline & 38. Ter carta de condução. & 17 \\
\hline & 18. Viver com o namorado/a. & 12 \\
\hline & 8. Ter 18 anos. & 11 \\
\hline & 3. Casar. & 11 \\
\hline & $\begin{array}{l}\text { 4. Quando uma mulher se tornar biologicamente capaz de ter } \\
\text { um filho. }\end{array}$ & 11 \\
\hline & 9. Ter um filho/a. & 8 \\
\hline & $\begin{array}{l}\text { 6. Quando um homem se torna biologicamente capaz de ter um } \\
\text { filho. }\end{array}$ & 4 \\
\hline & 13. Ter iniciado a vida sexual. & 4 \\
\hline \multirow{7}{*}{ 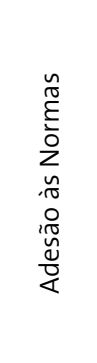 } & 20. Ser responsável pelos seus actos. & 96 \\
\hline & $\begin{array}{l}\text { 28. Evitar cometer delitos, como pequenos furtos e actos de van- } \\
\text { dalismo. }\end{array}$ & 70 \\
\hline & 34. Conduzir com segurança e respeitando os limites de velocidade. & 60 \\
\hline & 7. Evitar conduzir alcoolizado. & 51 \\
\hline & 30. Evitar embriagar-se. & 36 \\
\hline & 16. Evitar o uso de palavrões e linguagem obscena. & 28 \\
\hline & 15. Ter apenas um parceiro sexual. & 21 \\
\hline
\end{tabular}




\begin{tabular}{|c|c|c|}
\hline Escalas & Itens & $\begin{array}{c}\% \\
\text { Concordância }\end{array}$ \\
\hline \multirow{6}{*}{ 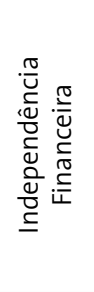 } & 2. Ser financeiramente independente dos pais. & 70 \\
\hline & 1. Ter uma carreira profissional estável. & 53 \\
\hline & 19. Ter um emprego a tempo inteiro. & 43 \\
\hline & 14. Comprar uma casa. & 42 \\
\hline & 11. Terminar os estudos. & 34 \\
\hline & 26. Não viver com os pais. & 25 \\
\hline \multirow{5}{*}{ 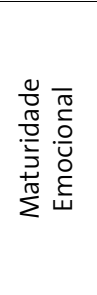 } & $\begin{array}{l}\text { 27. Decidir de acordo com as suas crenças e valores independen- } \\
\text { temente da influência dos pais ou outros. }\end{array}$ & 90 \\
\hline & $\begin{array}{l}\text { 33. Tornar-se menos centrado sobre si próprio e desenvolver uma } \\
\text { maior consideração pelos outros. }\end{array}$ & 81 \\
\hline & 25. Aprender a ter controlo sobre as emoções. & 70 \\
\hline & 29. Estabelecer compromissos a longo-prazo com outros. & 65 \\
\hline & 10. Ter uma relação “de igual para igual” com os pais. & 41 \\
\hline
\end{tabular}

Os marcadores considerados como mais relevantes pelos participantes, na definição da idade adulta, foram: ser responsável pelos seus actos, com 96\% de concordância, seguido de decidir de acordo com as suas crenças e valores independentemente da influência de pais ou outros (90\%); e tornar-se menos centrado sobre si próprio (81\%). Estes resultados realçam que é a capacidade do indivíduo para ser auto-suficiente e autónomo, de um ponto de vista psicológico e emocional, que é considerado marcante para se ser adulto. Como se poderá constatar, esses itens fazem parte da subescala maturidade emocional (com excepção do item ser responsável pelos seus actos pertencente à subescala adesão às normas). No extremo oposto, as transições mais normativas são aquelas que foram percepcionadas como menos importante na definição da idade adulta (<18\%). Os itens que recolheram menos percentagens de concordância foram: ter um filho (8\%); quando um homem se torna biologicamente capaz de ter um filho (4\%) e ter iniciado a vida sexual (4\%). Os itens pertencentes às escalas competências familiares, adesão a normas e independência financeira foram reconhecidos, em geral, como relativamente importantes na concepção da idade adulta. Com o intuito de verificar, estatisticamente, se, para os jovens da amostra, a entrada na idade adulta se fazia mais a partir dos marcadores sociais e demográficos clássicos, ou mais através de indicadores de intra-psíquicos, comparou-se, de seguida, as respostas destas duas escalas (análise da variância com medidas repetidas). Os dados revelam uma maior valorização da subescala maturidade emocional relativamente à subescala transições normativas $[F(1,212)=1057.23 ; p<.00]$ (Quadro 4). Estes resultados permitem-nos concluir que, para os estudantes da amostra, a entrada na idade adulta se faz, essencialmente, a partir de indicadores maturidade individual (maturidade emocional) e não através dos marcadores demográficos clássicos, representados aqui pela subescala de transições normativas. 
Quadro 4. Descritivas das dimensões do QMA

\begin{tabular}{lccc}
\hline Escalas & Média & Desvio-padrão & N \\
\hline Competências familiares & 2.57 & .59 & 215 \\
\hline Transições normativas & 1.53 & .37 & 213 \\
\hline Adesão às normas & 2.52 & .52 & 218 \\
\hline Independência financeira & 2.44 & .52 & 216 \\
\hline Maturidade emocional & 2.81 & .45 & 213 \\
\hline
\end{tabular}

Finalmente, a auto-percepção do estatuto de adulto pode ser um elemento relevante no modo como os jovens conceptualizam a idade adulta. Os resultados da análise de variância (one-way ANOVA) (Quadro 5) indicam-nos que a auto-percepção do estatuto de adulto influencia somente a valorização atribuída à independência financeira. Deste modo, os jovens que se consideram numa posição de ambivalência relativamente ao estatuto de adulto valorizam mais estes aspectos na definição da idade adulta, do que os jovens que já se auto-percepcionam como adultos.

Quadro 5. Marcadores de Adultez: Análise de variância, médias e desvio-padrão em função da auto-percepção do estatuto de adulto

\begin{tabular}{|c|c|c|c|c|c|c|c|c|c|c|c|c|}
\hline \multirow[t]{2}{*}{ Variáveis } & \multicolumn{3}{|c|}{ Sim } & \multicolumn{3}{|c|}{ Sim e Não } & \multicolumn{3}{|c|}{ Não } & \multicolumn{3}{|c|}{ ANOVA } \\
\hline & $M$ & $\mathrm{DP}$ & $\mathrm{N}$ & $M$ & $\mathrm{DP}$ & $\mathrm{N}$ & $M$ & DP & $\mathrm{N}$ & $\mathrm{F}$ & $p$ & Post-hoc \\
\hline Competências familiares & 2.53 & .56 & 84 & 2.60 & .62 & 103 & 2.61 & .61 & 27 & .34 & .71 & \\
\hline $\begin{array}{l}\text { Transições biológicas, legais } \\
\text { e sociais }\end{array}$ & 1.60 & .40 & 83 & 1.50 & .35 & 104 & 1.46 & .36 & 27 & 2.37 & .09 & \\
\hline Adesão às normas & 2.54 & .52 & 85 & 2.57 & .51 & 104 & 2.35 & .54 & 27 & 1.95 & .15 & \\
\hline Independência Financeira & 2.31 & .55 & 84 & 2.52 & .49 & 104 & 2.46 & .58 & 26 & 3.61 & .03 & $b, c>a$ \\
\hline Maturidade emocional & 2.82 & .50 & 84 & 2.84 & .42 & 105 & 2.69 & .41 & 27 & 1.24 & .29 & \\
\hline
\end{tabular}

\section{Discussão e Conclusões}

A transição para a idade adulta e a própria caracterização da idade adulta e dos seus marcadores tem sofrido alterações marcantes por força de transformações nos contextos sociais. Deste modo, verifica-se que os marcadores que, classicamente, assinalavam a entrada na idade adulta tendem a perder a sua importância em determinadas culturas, a favor de outros marcadores que se aproximam mais de dimensões psicossociais, nem sempre relacionados com o exercício de papéis de adulto.

Tendo em vista a análise da importância destes marcadores de idade adulta, procedeu-se à adaptação e estudo do Questionário de Marcadores de Adultez 
de Arnett (2001) junto de uma amostra de jovens portugueses. O instrumento apresenta uma estrutura de 5 factores que correspondem respectivamente a competências familiares, transições normativas, adesão às normas, independência financeira e maturidade emocional. Os coeficientes alfa de Cronbach oscilaram entre .91 e .76, sendo apenas inferior para uma das dimensões - .64 (maturidade emocional). Assim, a generalidade dos resultados obtidos, pelas a nálises factoriais exploratórias, confirmatórias e pela análise da consistência interna dos factores obtidos legitimam a importância da utilização do questionário para avaliação de dimensões sociais e psicológicas que, de acordo com a literatura, podem constituir marcadores da idade adulta no contexto nacional. Contudo, uma limitação a salientar neste estudo encontra-se associada ao facto das análises factoriais confirmatórias terem sido conduzidas sobre a mesma amostra. Adicionalmente, é também, importante notar que a consistência interna da sub-escala de maturidade emocional apresenta valores relativamente fracos, pelo que se sugere a necessidade de desenvolvimento posterior desta escala e o seu estudo mais aprofundado com outras amostras. Para além disso, o presente estudo incidiu, exclusivamente, sobre uma amostra de estudantes universitários. Sugere-se, também, que o instrumento seja estudado em amostras com características mais diversificadas, como por exemplo jovens de diferentes níveis socioeconómicos e com diferentes percursos escolares ou exercendo uma actividade profissional.

Apesar destas limitações o estudo permitiu, ao nível da análise de percepção individual sobre a adultez, obter resultados que se situam na linha do que tem sido encontrado em diversos estudos conduzidos por Arnett (1994, 1997, 1998, 2001). O facto de não se sentir adulto ou a ambivalência em relação a auto-percepção do estatuto de adulto está presente na maioria dos adultos emergentes. Esta é, aliás, uma das principais características desta etapa do ciclo de vida. De acordo com o autor, os adultos emergentes afirmam que se consideram adultos, por exemplo do ponto de vista legal, mas ao nível do exercício de papéis de adulto ou da capacidade de terem uma vida independente, ainda não se percepcionam como tal. Deste modo, os adultos emergentes estão numa posição intermédia entre a adolescência e a idade adulta, sendo que, de acordo com os resultados obtidos, esta ambivalência é mais notória para os estudantes que partilham a residência com os pais. É importante salientar que, na sociedade portuguesa, o estatuto de estudante a tempo inteiro é dominante, sendo tal situação apenas possivel graças ao apoio instrumental dado pelos pais durante a frequência do ensino superior. Ora, a manutenção da residência conjunta com os progenitores durante este período pode fomentar uma extensão do comportamento protector dos pais em relação aos filhos. Este poderá traduzir-se na manutenção de regras de convivência familiar e pela exigência de sucesso escolar, elementos susceptíveis de prolongar o tipo de relação estabelecida na adolescência. Deste modo, os pais, 
ao relacionarem-se tendencialmente com os filhos de um modo semelhante ao da etapa anterior (a adolescência), poderão contribuir para uma percepção de maior ambivalência no acesso à adultez (ser e não ser adulto), junto dos jovens que coabitam com os pais, por comparação com aqueles que partilham a residência com pares e que podem assim manter maior autonomia em relação à supervisão e ao controlo parental.

Foi, ainda, possivel verificar que, tal como foi identificado por Arnett (1994, 1997, 1998), os jovens da nossa amostra que a entrada na idade adulta faz-se principalmente através de marcadores de maturidade psicológica. A sub-escala de maturidade emocional é aquela que, apesar das fraquezas já assinaladas, parece captar melhor a percepção de adultez da maioria dos jovens participantes. Nesta dimensão são salientados aspectos que se referem à capacidade do indivíduo para ser independente, do ponto de vista emocional e instrumental, e ter interiorizado a "noção do outro", distanciando-se, assim, do egocentrismo característico da adolescência. Verifica-se que os marcadores externos de adultez, associados a parâmetros biológicas, legais e a acontecimentos sociais são, de uma forma geral, percepcionados como pouco relevantes na definição da idade adulta. Estes resultados são ainda mais interessantes por se manifestarem numa sociedade considerada familista (Matias \& Fontaine, 2005; Fontaine et al., 2006) onde aspectos associados à coesão e ao apoio familiar, quer em termos económicos, quer em termos familiares, são importantes para a transição para a idade adulta. Ora foram apenas percepcionados como medianamente relevantes enquanto se previa uma maior adesão a aspectos que realçam o exercício de papéis familiares.

Em suma, parece que o modo como, tradicionalmente, se tende a definir a idade adulta, partindo de critérios demográficos e sociais, pode não corresponder à percepção de adultez da maioria dos jovens da amostra. Estas percepções poderão ser, por um lado, influenciados pelas dificuldades que os jovens sentem actualmente para efectuarem as transições que, tradicionalmente, marcavam a entrada para a idade adulta, valorizando assim, aspectos mais internos e psicológicos. Por outro lado, poderão, também, ser o reflexo de mudanças nos valores e nas representações referentes a esta fase da vida. Assim, os resultados obtidos vão de encontro a um conjunto de estudos efectuados noutros países, com valores culturais distintas, (Arnett, 1998, 2001; Facio \& Micocci, 2003; Mayseless \& Scharf, 2003). Parece, deste modo, haver uma visão comum no que se refere à representação da idade adulta, em países ocidentais e industrializados. De facto, Portugal, nas últimas décadas tem sofrido profundas mudanças sociais, influenciando o modo como a transição para a idade adulta é actualmente vivenciada pelos jovens. O processo de globalização e a presença de uma sociedade mais exigente e competitiva encontra-se associado a inserções laborais difíceis e instáveis e, consequentemente, a uma maior dependência na família de origem. Deste modo, é provável que haja uma maior 
valorização de aspectos que se centrem na questão da autonomia e responsabilidade pessoal dos jovens. Contudo, seria útil explorar as razões da desvalorização relativa dos marcadores associados ao exercício de papéis familiares em estudos posteriores com amostras mais heterogéneas.

Para além disto, destaca-se, também, o facto dos marcadores que evidenciam aspectos associados à independência financeira serem percepcionados como mais relevantes pelos jovens que, ainda, não se percepcionam completamente como adultos. Embora, neste estudo não tivesse sido recolhida informação sobre a situação económica dos participantes, sabe-se, no entanto, que a maior parte dos estudantes em Portugal são dependentes do a poio económico dado pelos pais. Tal situação poderá contribuir para tornar este critério particularmente saliente na sua auto-percepção como adultos, que vêem a independência financeira como fundamental para futuras transições e a experimentação de futuros papéis de adulto.

Em suma, apesar do papel relevante das transformações sociais actuais nos contornos do processo de transição para a idade adulta, a representação da idade adulta pelos jovens está, na actualidade, assente em critérios de natureza psicológica e como tal individual, e menos em critérios que sejam socialmente determinados. Esta representação parece estar, assim, em consonância com uma sociedade pautada por novos valores menos consensuais e que surge como menos previsivel e mais incerta.

\section{Referências bibliográficas}

Alves, N. (1998). Escola e trabalho: Atitudes, projectos e trajectórias. In Cabral, M.V. e Pais, J. M. (eds.), Jovens Portugueses de Hoje (pp.53-133). Oeiras: Celta Editora.

Andrade, C. (2006). Antecipação da conciliação dos papéis familiares e profissionais na transição para a idade adulta: estudo diferencial e intergeracional. Dissertação de Doutoramento, Faculdade de Psicologia e de Ciências da Educação da Universidade do Porto.

Arnett, J. J. (1994). Are college students adults? Their conceptions of the transition to adulthood. Journal of Adult Development, 1, 154-168.

Arnett, J. J. (1997). Young people's conceptions of the transition to adulthood. Youth and Society, 29, 3-23.

Arnett, J. J. (1998). Learning to stand alone: The contemporary American transition to adulthood in cultural and historical context. Human Development, 41, 295-315.

Arnett, J. J. (2000). Emerging adulthood: A theory of development from late teens through the twenties. American Psychologist, 55, 469-480.

Arnett, J. J. (2001). Conceptions of the transition to adulthood: perspectives from adolescence through midlife. Journal of Adult Development, 8, 133-143.

Arnett, J. J. (2004). Emerging Adulthood. New York: Oxford University Press. 
Arnett, J. J. (2006). Emerging adulthood: Understanding the new way of coming of age. In J. Arnett \& L. Tanner (Eds). Emerging adulthood in America: Coming of age in the $27^{\text {st }}$ Century (pp.. 3-19). Washington, DC. American Psychological Association.

Barrisco, S. (2006). Família. In V. S. Ferreira (Coord.). A condição juvenil portuguesa na viragem do milénio. IPJ: Instituto Português da Juventude.

Cavalli, A. (1997). The delayed entry into adulthood: Is it good or is it bad for society? Actas do Congresso Internacional Growing up Between Center and Periphery. Lisbon: Instituto de Ciências Sociais.

Côté, J. (2000). Arrested adulthood: The changing nature of maturity and identity. New York: New York University Press.

Côté, J. (2006). Emerging adulthood as an institutionalized moratorium: Risks and benefits to identity formation. In J. Arnett \& L. Tanner (Eds). Emerging adulthood in America: Coming of age in the $27^{\text {st }}$ Century (pp. 85-116). Washington, DC. American Psychological Association.

Erikson, E. (1968). Identity: Youth and crisis. New York. Norton.

Facio, A., \& Micocci, F. (2003). Emerging adulthood in Argentina. New directions for Child and Adolescent Deveopment, 100, 21-31.

Fontaine, A. M., Andrade, C., Matias, M., Gato, J. \& Mendonça, M. (2006). Valeurs de jeunes couples à double revenue. Comparasion interculturelle en Europe. La revue international de l'éducation familiale, 19, 31-51.

Fontaine, A, M. \& Matias, M. (2003). Familismo e individualismo em jovens adultos: Construção de um instrumento e estudos exploratórios. Revista Galego-Portuguesa de Psicoloxia e Educación, 10, 2348-2362.

Gordan, T., Holland, J., Lahelma, E. \& Thomson, R. (2005). Imagining gendered adulthood: anxiety, ambivalence, avoidance and anticipation. European Journal of Women's studies, 12 (1), 81-103.

Guerreiro, M. D., Abrantes, P. (2004). Moving into adulthood in a Southern European country: Transitions in Portugal. Revista Portuguesa de Ciências Sociais, 3 (3), 191-209.

Guerreiro, M. D. \& Abrantes, P. (2007). Transições incertas. Os jovens perante o trabalho e a familia. CITE: Lisboa.

INE, Instituto Nacional de Estatítica. (2004). Estatísticas do emprego. Consultado em Dezembro 2006, http//: www.ine.pt.

Mayseless, O., Scharf, M. (2003). What does it mean to be an adult? The Israeli experience. New directions for Child and Adolescent Deveopment, 100, 5-20.

Pais, J. M. (2001). Ganchos, tachos e biscates. Lisboa: Editora Âmbar.

Schlegel, H., \& Barry, H. (1991). Adolescence: An anthropological inquiry. New York: Free Press.

Shanahan, M., Porfeli, E., Mortimer, J. (2005). Subjective age identity and the transition to adulthood: When does one become an adult? Press.

Sousa, F. (2007). O que é "ser adulto": As práticas e representações sociais sobre o que é "ser adulto" na sociedade portuguesa. Revista Moçambras: Acolhendo a alfabetização nos paises de lingua portuguesa, 1.(2), 56-69. Consultado em Setembro 2007, http:// www.moçambras.org.

Tanner, J. L. (2006) Recentering during Emerging Adulthood: A critical turning point in the life span human development. In J. Arnett \& L. Tanner (Eds). Emerging adulthood in America: Coming of age in the $27^{\text {st }}$ Century (pp. 21-55). Washington, DC. American Psychological Association. 
Vasconcelos, P. (1998). Práticas e discursos de conjugalidade e de sexualidade dos jovens portugueses. In M. V. Cabral e J. M. Pais (org). Jovens Portugueses de Hoje (pp. 215305). Oeiras: Celta Editora.

Vieira, J. (2006). Emprego. In V. S. Ferreira (Coord.). A condição juvenil portuguesa na viragem do milénio. IPJ: Instituto Português da Juventude.

Westberg, A. (2004). Forever young? Young people's conception of adulthood: The Swedish case. Journal of Youth Studies, 7 (1), 35-53.

\section{Transition vers l'âge adulte et adultes émergents: adaptation du Questionnaire de Marqueurs de l'Âge Adulte à de jeunes portugais}

Cet article présente l'adaptation du Questionnaire of Markers of Adulthood (Arnett, 2001) à un échantillon portugais. Inspiré du concept de Age Adulte Emergent, les marqueurs de transition psychologiques, biologiques, sociaux et contextuels ont été mesurés à partir 37 items auprès de 224 étudiants universitaires portugais.

Des analyses factorielles exploratoires et confirmatoires ont mis en évidence une structure en cinq dimensions. Les résultats confirment l'importance des marqueurs psychologiques comme éléments nucléaires dans la définition de l'identité adulte. En outre, pour les jeunes de l'échantillon qui ne se considèrent pas encore adultes, l'indépendance financière a aussi été évaluée comme un élément crucial de leur définition de l'âge adulte.

Cette étude renforce l'importance attribuée par de nombreux auteurs contemporains à cette phase de vie émergente et présente un instrument capable d'évaluer de façon fidèle et valide, l'importance relative des marqueurs de conceptualisation de la transition vers l'âge adulte au Portugal.

MOTS-CLÉS: adulte émergent; marqueurs d'âge adulte; qualité psychométrique.

\section{Transition to adulthood and emerging adulthood: adaptation of the Questionnaire of markers of adulthood among portuguese youth}

This paper reports on the adaptation of the Questionnaire of Markers of Adulthood (Arnett, 2001) to a Portuguese sample. Inspired in the concept of Emerging Adulthood, psychological, biological, social and contextual transitional markers were measured by 37 items. By using data from a sample of Portuguese college students $(N=224)$, validity evidence was provided by a five-dimensional structure of the questionnaire. Additionally, the results generally supported the hypothesized importance of psychological markers as key points in the definition of adulthood. Moreover, in the sub-samples of emergent adults who do not clear perceive themselves as adults', financial independence was also valued as a key point for their self-definition of adulthood.

This study contributes to current literature on emerging adulthood and offers a reliable and valid tool to measure the importance of transitional markers on the conceptualization of adulthood in Portugal.

KEY-WORDS: emerging adulthood; markers of adulthood; psychometric qualities. 